\title{
Oxidative Stress of Cadmium-Induced Ovarian Rat Toxicity
}

\author{
J. A. Tribowo, M. H. Arizal, M. Nashrullah, A. R. Aditama, and D. G. Utama
}

\begin{abstract}
Cadmium (Cd), a common toxic heavy metal, is widely distributed in the environment due to its use in industry. In the industry, $\mathrm{Cd}$ is hazardous both by inhalation and ingestion and can cause acute and chronic toxicity. Exposure to Cd had been known to cause damage to organs such as kidney, liver and testis. In this present study $\mathrm{Cd}$ was proposed caused an oxidative stress in ovarian rat (Rattus novergicus) cells. Female Rattus novergicus was divided in two groups, one control groups and one case group were exposed by $\mathrm{Cd}$. Furthermore we set Superoxidismutase (SOD), Peroxidase (POX) and catalase (CAT) activity with Hydrogen peroxide $\left(\mathrm{H}_{2} \mathrm{O}_{2}\right)$ and Malondyaldehide (MDA) as a biomarker of oxidative stress. For analyzing of the data, SPSS software version 17 was used and was examined by Mean-Whitney test. For all outcomes, a nominal $p$-value of $p<0.05$ was considered significant. The resulted showed that there are a significance differences SOD, GPx and catalase activity between case and control group. The resulted also showed a significance differences $\mathrm{H}_{2} \mathrm{O}_{2}$ and MDA levels between case and control group. The result suggest that Cd induced oxidative stress in ovarian cells.
\end{abstract}

Index Terms-Antioxidant enzym, cadmium, ovarian cells and oxidative stress.

\section{INTRODUCTION}

Cadmium (Cd) is a heavy metal used in batteries production and for special alloys. Although emissions in the environment have markedly declined in most industrialized countries, $\mathrm{Cd}$ remains a source of concern for industrial workers and for populations living in polluted areas, especially in developed countries. In the industry, $\mathrm{Cd}$ is hazardous both by inhalation and ingestion and can cause acute and chronic toxicity. $\mathrm{Cd}$ dispersed in the environment can persist in soils and sediments for decades. When taken up by plants, $\mathrm{Cd}$ concentrates enter the food chain and ultimately accumulates in the body of people eating contaminated foods. $\mathrm{Cd}$ is also present in cigarette smoke, further contributing to human exposure. Furtheremore, the most salient toxicological property of $\mathrm{Cd}$ is its exceptionally long half-life in the human body. Once absorbed, $\mathrm{Cd}$ accumulates in the human body, and other vital organs such the lungs, kidney or the liver and caused oxidative stress. Oxidative stress occurs when there is an inbalance between reactive oxygen species (ROS) and antioxidative defense [1]-[3].

ROS are considered to be unavoidable by-products of normal aerobic metabolism. However, many stresses can

Manuscript received October 24, 2013; revised January 10, 2014.

The authors are with Faculty of Medicine Lambung Mangkurat University South Kalimantan, Indonesian (email: jefryat@yahoo.com, hendyarizal@yahoo.com, arul3592@gmail.com, akbarsyah.ridar.aditama @ gmail.com, damargilang.utama@gmail.com). disrupt cellular homeostasis, thus enhancing the production of ROS [4]. These ROS react with lipids, proteins, pigments and nucleic acids, causing lipid peroxidation. As a result of ROS attack, lipids are oxidized and hence membranes are damaged. MDA, a well-known secondary product of lipid peroxidation after exposure to ROS Beside of that, ROS can caused membrane damage and enzyme inactivation. The effect of $\mathrm{Cd}$ exposure in drinking water on markers of oxidative stress in rat cardiac tissue has shown significantly increased lipoperoxides, MDA and decreased activities of SOD and POX [5]. Kevin Dzobo et al. 2013, showed that Cd induces oxidative stress and depletes antioxidant enzymes in rat kidneys and testes [6].

Acute exposure to $\mathrm{Cd}$ in vivo causes dysuria, polyuria, chest pain, fatigue, headache, and hepatooxidative. Chronic intake of $\mathrm{Cd}$ in contaminated food or air produces organ dysfunction as a result of cell death, resulting in pulmonary, hepatic and renal tubular diseases [7].

$\mathrm{Cd}$ also affects reproductive organs especially ovarium. Basic histological studies showed that in the ovary Cd causes a decrease in the number of primary follicles. The number of atretic follicles was significantly higher after $\mathrm{Cd}$ administration. In the other study, massanyi et al. prove the negative effect of Cd on the ovarian structure [8], [9].

Many studies suggested that generation of ROS and its interference with cellular antioxidant system is one of the major mechanisms by which toxic effect of $\mathrm{Cd}$ is mediated. $\mathrm{Cd}$ has been associated with occurence of increased oxidative stress and cancer [10]. Cd generates ROS which depletes endogenous ROS scavengers and long term exposure to $\mathrm{Cd}$ increased lipid peroxidation and caused inhibition of SOD activity indicating oxidative damage in liver [7]. Animal studies have shown that $\mathrm{Cd}$ can stimulate formation of reactive oxygen species (ROS) and induce damage to various tissues [10]. However there is few studies on the mechanism oxidative stress in ovarium exposed to heavy metal such as $\mathrm{Cd}$ are available. Thus the aim of the present study was to investigate the effect of $\mathrm{Cd}$ in ovarium rat through the stress oxidative mechanism.

\section{MATERIAL AND METHODS}

The present study was a true experimental study with post-test-only and control group design to examine the impact of $\mathrm{Cd}$ exposure in ovarian rats (Rattus novergicus) with 10 weeks of age and weighing 200-250 grams.. The study involved 2 groups of 40 female rats (Rattus novergicus), where one group was the control group, while the other was the case group with exposure of $\mathrm{Cd}$.

The control group rats were given $2 \mathrm{ml}$ of distilled water 
with a sonde every morning while in the treatment group rats were exposed $\mathrm{Cd}$. After 4 weeks, the mice were sacrificed using ether and then decapitated and performed surgery to take out the ovaries.

Ovaries were washed with phosphate buffer $\mathrm{pH} 7$, then ground up into a liquid. Then taken and $5 \mathrm{ml}$ centrifuge with a speed of $3500 \mathrm{rpm}$ for 10 minutes. After that, $200 \mathrm{~mL}$ of supernatant was taken for examination

\section{A. Data Analysis}

\section{1) Determination of SOD activity}

The SOD activity in supernatant was measured by the method of Misra and Fridovich [11]. The supernatant (500 $\mu 1)$ was added to $0.800 \mathrm{ml}$ of carbonate buffer (100 mM, pH 10.2) and $100 \mu \mathrm{l}$ of epinephrine $3 \mathrm{mM})$. The change in absorbance of each sample was then recorded at $480 \mathrm{~nm}$ in spectrophotometer for $2 \mathrm{~min}$ at an interval of $15 \mathrm{sec}$.

\section{2) Determination of peroxidase activity}

Determination of Peroxidase activity was measured by method of Pruitt et al. [12]. The assay was performed by mixing $1.0 \mathrm{ml}$ phosphate buffer ( $\mathrm{pH} 7.0), 1.0 \mathrm{ml}$ guaiacol solutionand $1.0 \mathrm{ml}$ of a saliva sample. The reaction was started by adding $1.0 \mathrm{ml}$ of $\mathrm{H}_{2} \mathrm{O}_{2}$ stock solution. Absorbance at $470 \mathrm{~nm}(\mathrm{~A})$ and time (T) data were monitored.

\section{3) Determination of catalase activity}

The activity of CAT was determined according to Aebi (1984) in $3 \mathrm{ml}$, of reaction media, which contained : Two ml of homogenizing medium (phosphate buffer pH7.0) in a test tube followed by $1 \mathrm{ml}$ of $\mathrm{H}_{2} \mathrm{O}_{2}$ solution. The blank was composed from : one ml buffer $\mathrm{pH} 7.0$ and $2 \mathrm{ml}$ tissue homogenate $(\mathrm{pH} 7.0)$. The extinction was measured at a wavelength of $240 \mathrm{~nm}$ using UV-Vis spectrophotometer.

\section{4) Determination $\mathrm{H}_{2} \mathrm{O}_{2}$ concentration}

Determination of $\mathrm{H}_{2} \mathrm{O}_{2}$ concentration by the modified FOX2 method [7]. Solutions measured spectrophotometrically at $\lambda=505 \mathrm{~nm}$.

\section{5) Determination of malondyaldehide}

MDA was measured by the method of Buege and Aust [7]. The colour was measured spectrophotometrically at $532 \mathrm{~nm}$. Ovary in the homogenization of $100 \mathrm{mg}$. Then add $1 \mathrm{~mL}$ aquadest then disposed of in thee pendorf. After that added $100 \%$ TCA $100 \mathrm{uL}, 1 \%$ Na-Thio $100 \mathrm{uL}$ and $250 \mathrm{uL}$ of $1 \mathrm{~N}$ $\mathrm{HCl}$. The solution is heated at a temperature of $1000{ }^{\circ} \mathrm{C}$ for 20 minutes. Then centrifuged to $3500 \mathrm{rpm}$ for 10 minutes. Supernatant was taken. After that, add distilled water up to $3500 \mathrm{uL}$. The result is read by a spectrophotometer with a maximum wavelength of 500-600 nm.

\section{B. Statistical Analysis}

Data are presented as means \pm SD. The differences were examined by the Mann-Withney test. For all outcomes, a nominal $p$-value of $p<0,05$ was considered significant.

\section{RESULT AND DISCUSSION}

The average antioxidant enzym activity case and control groups are presented in Table I.
TABLE I: ANTIOXIDANT ENZYM ACTIVITY IN OVARIAN RATS

\begin{tabular}{lccc}
\hline \hline Antioxidant Enzym & Case Group & $\begin{array}{c}\text { Control } \\
\text { Group }\end{array}$ & P Values \\
\hline SOD $\left(\mu \mathrm{M} \mathrm{min}^{-1}\right)$ & $0,070 \pm 0,073$ & $0,005 \pm 0,003$ & 0,000 \\
Peroxidase $\left(\mu \mathrm{M} \mathrm{min}{ }^{-1}\right)$ & $1,595 \pm 1,256$ & $0,454 \pm 0,268$ & 0,000 \\
Catalase & $0,630 \pm 0,142$ & $0,539 \pm 0,125$ & 0,037 \\
\hline \hline
\end{tabular}

*) = a significant difference/ significantly $(p<0.05)$

Mean-Whitney test results showed that there were significant differences between case and control groups ( $p$ $<0.05)$.

Occupational exposure to $\mathrm{Cd}$ has been associated with occurence of increased oxidative stress. Oxidative stress is a harmful condition that occurs when there is an inbalance between ROS, including superoxide, hydrogen peroxide and hydroxyl radicals, and/or by inadequate antioxidative defences, including SOD, CAT, and POX. An interesting mechanism explaining the indirect role of $\mathrm{Cd}$ in free radical generation was presented some years ago [13].

$\mathrm{Cd}$ itself is unable to generate free radicals directly, however, indirect formation of ROS and RNS involving the superoxide radical, hydroxyl radical and nitric oxide has been reported. Some experiments also confirmed the generation of non-radical hydrogen peroxide which itself in turn maybe a significant source of radicals via Fenton chemistry. Cd can activate cellular protein kinases (protein kinase C) which result in enhanced phosphorylation of various transcription factors which in turn lead to activation of target gene expression [10], [14], [15].

In this mechanism it was proposed that $\mathrm{Cd}$ can replace iron and copper in various cytoplasmic and membrane proteins (e.g. ferritin, apoferritin), thus increasing the amount of unbound free or chelated copper and iron ions participating in oxidative stress. Displacement of copper and iron by $\mathrm{Cd}$ can explain the enhanced Cd-induced toxicity, because copper displaced from its binding site, is able to catalyze breakdown of hydrogen peroxide via the Fenton reaction. These results are supported by recent findings by Watjen and Beyersmann (2004). Displacement of copper and iron by Cd can explain the enhanced cadmium-induced toxicity, because copper, displaced from its binding site, is able to catalyze breakdown of hydrogen peroxide via the Fenton reaction [16].

The toxic mechanisms of cadmium are not well understood, but it is known to act intracellularly, mainly via free radical-induced damage, particularly to the lungs, kidneys, bone, central nervous system, reproductive organs and heart [17].

The effect of cadmium exposure in drinking water on markers of oxidative stress in rat cardiac tissue has shown significantly increased lipoperoxides, MDA and decreased activities of SOD and glutathione peroxidase (GPx). No alterations were observed in catalase activity. In addition, decreased glucose levels and increased total lipid content in cardiac tissue of rats following cadmium exposure were observed. The decreased activities of alanine transaminase and aspartate transaminase reflected decreased metabolic protein degradation and increased lactate dehydrogenase activity. Since the metabolic pathways were altered by cadmium exposure, it can be concluded that $\mathrm{Cd}^{2+}$-induced formation of ROS initiates a series of events that occur in the 
heart which in turn resulted in alterations of metabolic pathways [17].

In this present study the results showed there is the increased of SOD, POX and CAT activity in ovarian rats.

SOD is considered a key enzyme in the regulation of intracellular concentrations of ROS. SOD acts as the first line of defense against ROS, dismutating superoxide to $\mathrm{H}_{2} \mathrm{O}_{2}$. Thus, increased SOD activity showed that it plays a positive role in controlling the cellular level of these ROS and/or repairing oxidative damage against free radicals by $\mathrm{Cd}$ stress [18].

In humans, there are three forms of SOD: cytosolic $\mathrm{Cu} / \mathrm{Zn}-\mathrm{SOD}$, mitochondrial Mn-SOD, and extracellular SOD. SOD destroys $\bullet \mathrm{O} 2$ by successive oxidation and reduction of the transition metal ion at the active site in a Ping Pong type mechanism with remarkably high reaction rates. All types of SOD bind single charged anions such as azide and fluoride, but distinct differences have been noted in the susceptibilities of $\mathrm{Fe}^{-}, \mathrm{Mn}^{-}$or $\mathrm{Cu} / \mathrm{Zn}-\mathrm{SODs}$. $\mathrm{Cu} / \mathrm{Zn}-\mathrm{SOD}$ is competitively inhibited by $\mathrm{N}^{-}, \mathrm{CN}^{-}$and by $\mathrm{F}$ [19].

As well as SOD, POX is a plays a vital role in protection of lipid membrane against oxidative damages. During oxidative stress induced $\mathrm{Cd}$, intermediary forms of oxygen, $\left(\mathrm{H}_{2} \mathrm{O}_{2}\right.$, hydroxyl and superoxide radicals) are formed. These very reactive molecules could be quenched by the induction of specific enzymes like POX, SOD and CAT stated that $\mathrm{Cd}$ enhances the level of lipid peroxidation and increasing tissue concentration of $\mathrm{H}_{2} \mathrm{O}_{2}$ in ovarian rat cells and causes oxidative damage. The increasing of POX activity in ovarian rat cells show that it was functioning concurrently to remove $\mathrm{H}_{2} \mathrm{O}_{2}[20]$.

CAT are ubiquitous heme enzymes that are found in aerobic organisms, ranging from bacteria to higher plants and animals. CAT is a tetramer of four polypeptide chains, each over 500 aminoacids long. It contains four porphyrin heme group that allow the enzyme to react with the hydrogen peroxide. Functionally, CAT are related to POX; both promote $\mathrm{H}_{2} \mathrm{O}_{2}$ oxidation by mechanisms that involve ferryl intermediates [21].

The reaction of CAT occurs in two steps. A molecule of hydrogen peroxide oxidizes the heme to an oxyferryl species. A porphyrin cation radical is generated when one oxidation equivalent is removed from iron and one from the porphyrin ring. A second hydrogen peroxide molecule acts as a reducing agent to regenerate the resting state enzyme, producing a molecule of oxygen and water [20].

In animals, hydrogen peroxide is detoxified by CAT and by POX. CAT protects cells from hydrogen peroxide generated within them. Even though CAT is not essential for some cell types under normal conditions, it plays an important role in the acquisition of tolerance to oxidative stress in the adaptive response of cells. Survival of rats exposed to $100 \%$ oxygen was increased when liposome's containing SOD and CAT were injected intravenously before and during the exposure. The increased sensitivity of transfected CAT-enriched cells to some drugs and oxidants is attributed to the property of CAT in cells to prevent the drug-induced consumption of $\mathrm{O}_{2}$ either for destroying $\mathrm{H}_{2} \mathrm{O}_{2}$ to oxygen or for direct interaction with the drug [19].

However $\mathrm{Cd}$ effect on antioxidant enzym is still controversial. It has been reported that $\mathrm{Cd}$ may induce oxidative damage in a variety tissue enchancing peroxidation of membran lipids due to inhibition of antioxidant enzym. Other authors have noted that $\mathrm{Cd}$ exposure might lead to lipid peroxidation, causing an increase in antioxidant enzym activities. The alteration of antioxidant enzym activities may depend on several factors such as, $\mathrm{Cd}$ dose, $\mathrm{Cd}$ exposure times, and type of $\mathrm{Cd}$ administration [21].

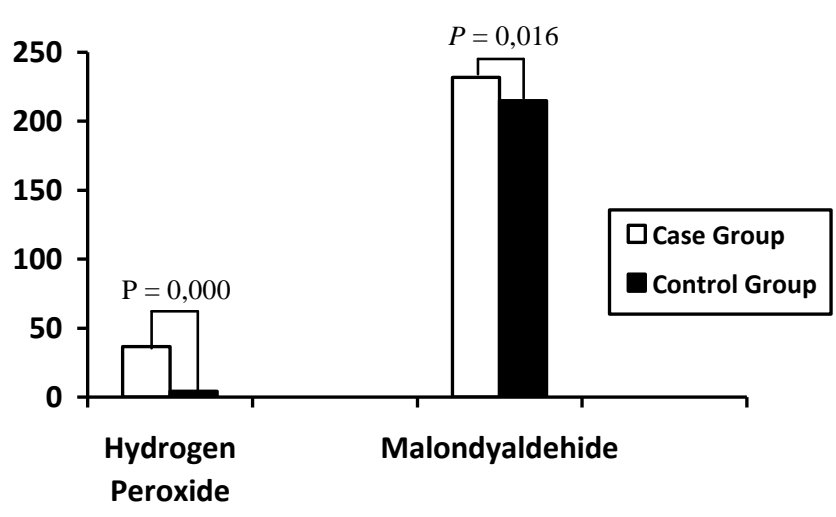

Fig. 1. Hydrogen Peroxide and Malondyaldehide levels in ovarian rats.

From Fig. 1 Mean of Hydrogen peroxide $\left(\mathrm{H}_{2} \mathrm{O}_{2}\right)$ and MDA levels in the ovarian rats from the Case group higher than the Control group. Mean-Whitney test results showed that there were significant differences between case and control groups $(p<0.05)$.

The increasing of $\mathrm{H}_{2} \mathrm{O}_{2}$ level in ovarian rats cells Cadmium indicates of lipid peroxidation.

It is known that metal-induced generation of oxygen radicals results in the attack of not only DNA but also other cellular components involving polyunsaturated fatty acid residues of phospholipids, which are extremely sensitive to oxidation [10].

The overall process of lipid peroxidation consists of three stages: initiation, propagation and termination. Initiation, the first stage, involves the attack of a ROS capable of abstracting a hydrogen atom from a methylene group in the lipid. The presence of a double bond adjacent the methylene group weakens the bond between carbon and hydrogen so the hydrogen can be more easily removed from the fatty acid molecule. Fatty acids with no double bonds or with onedouble bond can undergo oxidation but not a chain lipidperoxidation process [17].

The process of hydrogen abstraction leaves behind a fatty acid having one unpaired electron. When oxygen is present in the surrounding tissues, the fatty acid radical can react with it leading to the formation of lipo-peroxyl radicals (ROO•). Once formed, lipo-peroxyl radicals ( $\mathrm{ROO} \bullet$ ) can be rearranged via a cyclization reaction to endoperoxides (precursors of malondialdehyde) with the final product of peroxidation process being MDA [22]. MDA is mutagenic in bacterial and mammalian cells and carcinogenic in rats. Increase in lipid peroxidation with increased MDA levels has been observed in a cadmium-induced experimental group of wistar albino rats. It has been reported in other research that administration of $\mathrm{Cd}$ via different routes causes increased lipid peroxidation in membranes of erythrocytes and tissues such as the liver, 
kidney, brain and testes where MDA is used as an indicator of oxidative damage [7], [10], [17].

MDA is one of the main manifestations of oxidative damage and has been found to play an important role in the toxicity of $\mathrm{Cd}$. MDA is well-known lipid peroxidation indicator and has been found to increase in the liver and kidneys after Cd exposure. Eko Suhartono et al 2013 in his research showed that the administration of $\mathrm{Cd}$ caused significantly increase of MDA and peroxide levels as compared to the control group $(p<0.05)$ [7]. The results of other studies showed that ethanol and Cd increased the serum and liver MDA concentrations $24 \mathrm{~h}$ after administration [4]. Haki Kara et al. 2002 suggest that single doses of different concentrations of $\mathrm{Cd}$ are administered the dose dependent increase in MDA levels in agreement with this knowledge [23].

The mechanism of oxidative stress in ovarium proposed in Fig. 2.

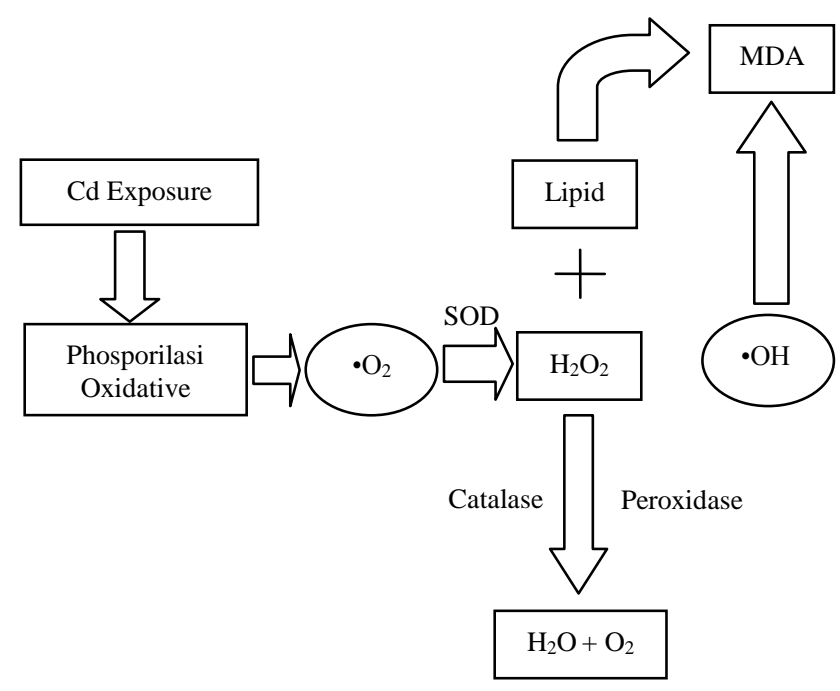

Fig. 2. Stress Oxidative mechanism in ovarian cells.

\section{CONCLUSION}

It can be concluded from presented results that $\mathrm{Cd}$ induced oxidative damage in ovarian rat cells by increased of antioxidant enzym activities and increased of MDA and hydrogen peroxide levels.

\section{ACKNOWLEDGMENT}

The authors are thankful to Iskandar, dr., Dr. dr.Adjar Wibowo, Sp.OG and Drs. Eko Suhartono, M.Si for his support and encouragement during the process of writing this research.

\section{REFERENCES}

[1] R. Wittman and H. Hu, "Cadmium exposure and nephropathy in a 28-year-old female metals worker," EHP, vol. 110, pp. 1261-1266, 2002.

[2] A. Bernard, "Cadmium \& Its adverse effects on human health," IJMR, vol. 128 , pp. 557-564, Oct. 2008.

[3] C. Y. Lin, M. Wu, J. A. Bloom, I. J. Cox, and M. Miller, "Rotation, scale, and translation resilient public watermarking for images," IEEE Trans. Image Process., vol. 10, no. 5, pp. 767-782, May 2001.
[4] T. Radosavljevic, D. Mladenovic, M. Ninkovic, D. Vucevic, I. Boricic, J. Vukicevic, T. Sljivancanin, S. Lopicic, and V. Todorovic, "Oxidative stress in rat liver during acute cadmium and ethanol intoxication," J. Serb. Chem. Soc, vol. 77, no. 2, pp. 159-176, 2012.

[5] M. Valko, H. Morris, and M. T. D Cronin,"Metals, toxicity and oxidative damage," Current Medicinal Chemistry, vol. 12, no. 10, 2005 .

[6] K. Dzobo and Y. S. Naik, "Effect of selenium on cadmium-induced oxidative stress and esterase activtiy in rat organs," S Afr J Sci, vol. 109, no. $5 / 6$, pp. $1-8,2013$

[7] E. Suhartono, Triawanti, A. Yunanto, R. T. Firdaus, and Iskandar, "Chronic cadmium hepatooxidative in rats: Treatment with Haruan fish (Channa striata) extract.” APCBEE Procedia, vol. 5, pp. 441-445, 2013

[8] P. Massanyi, V. Uhrin, R. Toman, J. Pivko, N. Luka, Z. S. Forgacs, Z. Somosy, M. Fabi, and J. Danko," Ultrastructural changes of ovaries in rabbits following cadmium administration," Acta. Vet. Brno, vol. 74, pp. 29-35, 2005.

[9] P. Nad, P. Massanyi, M. Skalicka, B. Korenekova, and V. Cigankova, "The effect of cadmium in combination with zinc and selenium on ovarian structure in Japanese quails," Rizikové faktory potravového ret'azca, vol. V., 2005.

[10] M. Valko, D. Leibfritz, J. Moncol, M. T. D. Cronin, M. Mazur, and J. Telser," Free radicals and antioxidants in normal physiological function and human disease," IJBCB, vol. 39, pp. 44-84, 2007.

[11] H. P. Misra and I. Fridovich, "The role of superoxide anion in the autooxidation of epinephrine and a simple assay for superoxide dismutase," JBC, vol. 247, no.10, pp. 3170-3175, June 1972

[12] H. R. Abdolsamadi, M. T. Goodarzi, H. Mortazavi, M. Robati, and F. A. Motemayel, "Comparison of salivary antioxidants in healthy smoking and non-smoking men," CGMJ, vol. 34, pp. 607-611, 2011.

[13] S. J. S. Flora, M. Mittal and A. Mehta, "Heavy metal induced oxidative stress and its possible reversal by chelation therapy," Indian J Med Res, vol. 128 , pp. 501-523, October 2008 .

[14] R. D. Kini, Y. Tripathi, C. V. Raghuveer, S. A. R. Pai, C. Ramaswamy, and P. Kamath, "Role of vitamin $\mathrm{C}$ as an antioxidant in cadmium chloride induced testicular damage," IJABPT, vol. 2, no. 3, pp. 484-488, July-Sept 2011.

[15] S. Vestena, J. Cambraia, C. Ribeiro, J. A. Oliveira, and M. A. Oliva,' Cadmium-induced oxidative stress and antioxidative response in water hyacinth and salvinia," Braz. J. Plant Physiol, vol. 23, no. 2, pp 131-139, 2011.

[16] K. Tremellen, "Oxidative stress and male infertility-a clinical perspective," Human Reproduction Update, vol. 14, no. 3, pp. 243-258, 2008.

[17] K. Jornova and M. Valko, "Advances in metal-induced oxidative stress and human disease," Toxicology, vol. 283, pp. 65-87, 2011.

[18] K. Muthukumar and V. Nachiappan,"Cadmium-induced oxidative stress in Saccharomyces cerevisiae," Indian J. Biochem. Biophys, vol. 47, pp. 383-387, December 2010.

[19] M.A. El-Missiry, Antioxidant eznym, Rijeka, Croatia : Intech, 2012, ch. 1, pp. 9-12.

[20] H. S. El-Beltagi, A. A. Mohamed, and M. M Rashed, "Response of antioxidative enzymes to cadmium stress in leaves and roots of radish (Raphanus sativus L.)," Not Sci Biol, vol. 2, no. 4, pp. 76-82, 2010.

[21] L. M. Sandalio, H. C. Dalurzo, M. Gomez, M. C. Romero P, and L. A. Del-Rio,"Cadmium-induced changes in the growth and oxidative metabolism of pea plants," J Exp Bot, vol. 52, no. 364, pp.2115-2126, November 2001.

[22] O. Tezcan, D. Pandir, and H. Bas, "The effects of cadmium on enzymatic antioxidant system and lipid peroxidation of human erythrocytes in vitro and the protective role of plasma levels of vitamins C and E," Pol. J. Environ. Stud, vol. 21, no. 6, pp. 1849-1854, 2012.

[23] H. Kara, F. Karata, and H. Canatan, "Effect of single dose cadmium chloride administration on oxidative stress in male and female rats," Turk J. Vet Anim Sci, vol. 29, pp. 37-42, 2005.

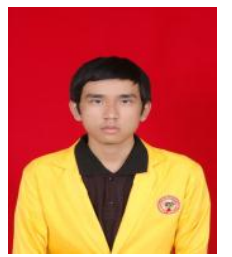

Jefry Albari Tribowo was born in Palembang South Sumatra, Indonesia, in June 1992. He currently study medical doctor in Faculty of Medicine Lambung Mangkurat University, Banjarbaru, Indonesia. 


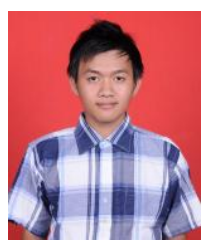

Muhammad Hendy Arizal was born in Kandangan South Kalimantan, Indonesia, in June 1993. He is currently studying medical doctor in Faculty of Medicine Lambung Mangkurat University, Banjarbaru, Indonesia.

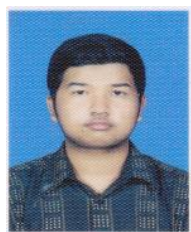

Muhammad Nashrullah was born in Banjarbaru South Kalimantan, Indonesia, in May 1992. He is currently studying medical doctor in Faculty of Medicine Lambung Mangkurat University, Banjarbaru, Indonesia.

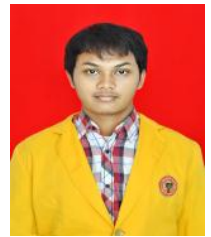

Akbarsyah Ridar Aditama was born in Yogyakarta West Java, Indonesia, in May 1992. He is currently studying medical doctor in Faculty of Medicine Lambung Mangkurat University, Banjarbaru, Indonesia.

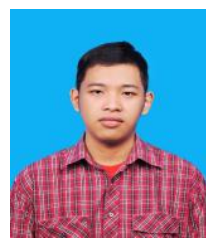

Damar Gilang Utama was born in Banjarbaru South Kalimantan, Indonesia, in February 1993. He is currently studying medical doctor in Faculty of Medicine Lambung Mangkurat University, Banjarbaru, Indonesia. 